\title{
Hate Speech, the Priority of Liberty, and the Temptations of Nonideal Theory
}

\author{
Robert S. Taylor
}

Accepted: 20 February 2011 / Published online: 25 May 2011

(C) Springer Science+Business Media B.V. 2011

\begin{abstract}
Are government restrictions on hate speech consistent with the priority of liberty? This relatively narrow policy question will serve as the starting point for a wider discussion of the use and abuse of nonideal theory in contemporary political philosophy, especially as practiced on the academic left. I begin by showing that hate speech (understood as group libel) can undermine fair equality of opportunity for historically-oppressed groups but that the priority of liberty seems to forbid its restriction. This tension between free speech and equal opportunity creates a dilemma for liberal egalitarians. Nonideal theory apparently offers an escape from this dilemma, but after examining three versions of such an escape strategy, I conclude that none is possible: liberal egalitarians are indeed forced to choose between liberty and equality in this case and others. I finish the paper by examining its implications for other policy arenas, including markets in transplantable human organs and women's reproductive services.
\end{abstract}

Keywords Hate speech · Priority of liberty · Nonideal theory $\cdot$ Equality of opportunity $\cdot$ Rawls

Are government restrictions on hate speech consistent with the priority of liberty? This relatively narrow policy question will serve as the starting point for a wider discussion of the use (and abuse) of nonideal theory in contemporary political philosophy, especially as it is practiced on the academic left. I hope to show that many if not most liberal egalitarians, following Rawls, are strongly committed to a set of basic liberties and their priorityespecially freedom of speech and rights over the body-but that such a commitment is in tension with their devotion to socio-economic equality. Nonideal theory offers an apparent means to resolve this tension, but I shall argue here that no such resolution is possible and that the tension remains intact, forcing liberal egalitarians to make, rather than avoid, some hard political choices.

To begin, however, I should define my terms. For reasons that will become clear below, I define "hate speech" as a type of group libel: speech (oral or written) that argues for the

R. S. Taylor $(\triangle)$

Department of Political Science \#1060, University of California, Davis, Davis, CA 95616-8682, USA

e-mail: rstaylor@ucdavis.edu 
mental, physical, and/or ethical inferiority of members of particular historically-oppressed groups (e.g., blacks, women, Jews, and homosexuals). Several other definitions of hate speech are available, of course, including ones that characterize it as "face-to-face vilification" by means of "fighting words" or as "hostile-environment harassment."1

Following Rawls and others, I distinguish between the "regulation" and the "restriction" of basic liberties like free speech. "The priority of these liberties," Rawls says, "is not infringed when they are merely regulated — as they must be - in order to be combined into one scheme as well as adapted to certain social conditions necessary for their enduring exercise" (Rawls 1993, 295). For instance, so-called "time, place, and manner" rules (e.g., scheduling speakers at a public forum on a "first-come, first-served" basis) usually qualify as regulations of speech, as they are merely intended to make communication mutually consistent or to protect the "central range of application" of other basic liberties. On the other hand, prohibitions on the advocacy of particular scientific or political doctrines count as restrictions of speech because they limit its content and thereby place at risk a core liberal value associated with open expression: intellectual autonomy achieved by way of the free exercise of public reason (Rawls 1993, 296; Kant 1996). Certain narrow limitations on the content of speech (e.g., bans on "fighting words," such as racial epithets used confrontationally) could be defended as regulations rather than restrictions, on the grounds that they do not threaten the free exercise of public reason and may protect the central range of application of other basic liberties (e.g., bodily security), but limitations on hate speech as I defined it above are prima facie restrictions, because they strike at the heart of such free exercise, which depends crucially on open access to all available arguments regarding scientific and political matters. ${ }^{2}$

Lastly, I define the "priority of liberty" in the orthodox Rawlsian manner, as the "special" (i.e., lexical or at least very high) priority of the equal-liberty (EL) principle over other principles of justice (e.g., the fair-equality-of-opportunity [FEO] principle or difference principle [DP]) and over other concerns as well (e.g., welfare, efficiency, perfection, piety, etc.) (Rawls 1993, 6, 156-157; Rawls 1999d, 266-267). EL guarantees a set of what Rawls refers to as "basic liberties," including but not limited to political liberty (i.e., the rights to vote and hold public office), freedom of speech and assembly, liberty of conscience and freedom of thought, freedom of the person (i.e., bodily and psychological integrity), and the right to hold personal property (Rawls 1999d, 53). Thus, I understand the priority of liberty as a limitation on possible reasons for curbing these basic liberties: such liberties cannot be restricted for the sake of FEO, the DP, efficiency, etc., but they can be regulated for reasons internal to EL itself (e.g., balancing against other liberties or implementation of the liberty in question). ${ }^{3}$

Rawls contends that assigning "special priority" to the basic liberties is not just a peculiar feature of justice as fairness but rather a defining quality of all liberal theories, and he is certainly correct that most contemporary liberals - be they classical liberals or liberal egalitarians - have a pronounced civil-libertarian bent (Rawls 1993, 6, 156-157). Still, one may question the extent to which liberals other than Rawls would endorse (near) absolute priority for the specific set of liberties listed above. Rawls himself notes that some basic liberties might be "less essential" than others, and he even suggests that "the case for certain

\footnotetext{
${ }^{1}$ All three of these possible definitions of hate speech - as group libel, fighting words, and hostileenvironment harassment - reflect those used in (previously) existing laws and regulations: see Brison (1998, 314-315)

2 See Altman $(1993,303-306)$ for a defense of the proposition that hate-speech restrictions are always "viewpoint-based" and therefore nonneutral.

${ }^{3}$ On justifying the lexical priority of liberty, see Freeman (2007, 64-79) and Taylor (2003, 246-271).
} 
political liberties and the rights of fair equality of opportunity" may be "less compelling" than that for "liberty of conscience and the rights defining the integrity of the person" (Rawls 1999d, 202, 217). Freedom of speech, as a requisite enabling condition for both liberty of conscience and freedom of thought, is surely one of these more essential basic liberties, however, and the history of liberal thought bears out its centrality: liberal thinkers ranging from John Stuart Mill to Rawls and Thomas Scanlon have adopted "extremism in defense of liberty" with respect to free speech, at least, and their arguments in its favor would protect hate speech as I defined it above. ${ }^{4}$ I will therefore assume for the remainder of this paper that liberals of all stripes either are or should be civil libertarians with respect to speech, including hate speech.

I also want to remain agnostic here about whether hate speech as I have defined it might be reasonably regulated for reasons internal to EL. I noted earlier that "fighting words" (such as racial epithets) might be so regulated, as their limitation does not threaten the free exercise of public reason and might help protect other central liberties, such as bodily security; liberties, in short, may have to be balanced against one another, and peripheral exercises of one liberty will reasonably give way to central exercises of another, equally important one. One can imagine rare situations - such as the calm delivery of a scholarly, epithet-free disquisition on the ethical and physical inferiority of Jews to an angry mob of anti-Semites gathered near Jewish businesses - in which even hate speech on my understanding of it might be reasonably regulated. ${ }^{5}$ Rather than focus on such cases, though, I want to concentrate instead on those whose curbs would genuinely qualify as restrictions and violations of the priority of liberty, not only because such cases have great prominence in the philosophical and legal literatures, including case law, but also because discussion of them will serve the larger aim of my paper, viz. examining the uses (and abuses) of nonideal theory. Consider the following two model cases:

1. Suppose that a law is proposed to punish (maybe only with fines) the advocacy of racially and sexually bigoted doctrines on the grounds that their spread would severely hinder the implementation of FEO: the dissemination of such doctrines in a population - especially among employers and college-admissions committees - would hamper the matching of people and their aptitudes with appropriate offices and positions in the basic structure of society. ${ }^{6}$ Such concerns over the contribution of hate speech to socioeconomic inequality

\footnotetext{
${ }^{4}$ See Mill (1998, 20-61), especially p. 26: "Strange it is, that men should admit the validity of the arguments for free discussion, but object to their being 'pushed to an extreme'; not seeing that unless the reasons are good for an extreme case they are not good for any case." Both Rawls and Scanlon carve out exceptions in their free-speech doctrines for "defamation," but it is clear from context that they mean defamation against individuals rather than groups; because hate speech as I define it necessarily involves arguments with respect to both scientific and political propositions, its restriction could not be consistent with Rawls's and Scanlon's rather robust commitments to the development and exercise of intellectual autonomy - on this point, see Rawls (1993, 299-324, 336) and Scanlon (1972, 209, 211, and 213 [specifically, the "Millian Principle" and the way it would deal with a causal connection between hate speech and discrimination]). In a less scholarly vein, the American Civil Liberties Union, commonly regarded as a liberal organization, is deeply critical of hate-speech codes on college campuses.

${ }^{5}$ Scholars have also argued for hate-speech regulations in order to maintain the fair value of political liberties and protect intellectual autonomy itself: e.g., see Brink (2001), Lawrence (1995, 116), Mann (1995, 260261), Michelman (1995, 273), and Sunstein (1991, 31-32).

${ }^{6}$ I will assume throughout this paper that such "hampering" takes place by means of illegal discriminatory behavior prompted by these bigoted doctrines. Such hampering could take place via behavior that falls short of illegality, e.g., subconscious tendencies to underestimate the talents of racial minorities - but perhaps this is only undetected (and rather difficult to detect) illegality. If we use a strict-liability standard (i.e., no mens rea requirement), subconscious discrimination may still be actionable upon proof of discriminatory outcomes by, say, statistical analysis of hiring decisions.
} 
can be found throughout the philosophical and legal literatures and in case law, especially the landmark group-libel case Beauharnais v. Illinois. ${ }^{7}$ Given its motivation, such a law would contravene the priority of liberty. ${ }^{8}$

2. Suppose that a law is proposed to punish (maybe only with fines) the advocacy of racially and sexually bigoted doctrines on the grounds that the significant pain they cause to some listeners/readers (especially those of the race or sex under attack) far outweighs whatever pleasure it gives to its speakers/writers and other listeners/readers. Again, concerns of this kind, which are at base utilitarian in nature, frequently arise in the philosophical and legal literatures. ${ }^{9}$ Given its welfarist intent, such a law would violate the priority of liberty.

The (identical) conclusions reached in these two cases may conflict sharply with the considered convictions of justice of liberal egalitarians and liberal utilitarians, whose respective partialities to socioeconomic equality and welfare-maximization are in tension with the liberal commitment to the priority of liberty. One can imagine that for many liberal utilitarians - especially those of a direct, act-utilitarian persuasion - this tension might be easily resolved in reflective equilibrium: for them, the priority of liberty is merely a highly valued rule of thumb, so in situations where it conflicts sharply with welfare-maximization, it must be duly circumscribed. ${ }^{10}$ The principle of justice-here, EL and its priority-would therefore give way to the considered conviction, albeit a rather abstract one. This would, of course, bring their liberal credentials into question (at least on Rawls's conception of liberalism), but that may bother them less than having their utilitarian bona fides in doubt.

I think that this tension will be much harder to resolve for most liberal egalitarians. Their commitment to socioeconomic equality - in particular, equality of educational and employment opportunities for historically-oppressed groups - is informed and strengthened

\footnotetext{
${ }^{7}$ In the philosophical and legal literatures, see Barnes (1995, 159), Brison (1998, 316), Delgado and Stefancic (1999, 6-8), and Meyers (1995, 203-205). The Supreme Court case Beauharnais v. Illinois (343 U. S. 250 [1952]) upheld an Illinois group-defamation statute that criminalized the exhibition or publication of pictures or writings that portrayed "depravity, criminality, unchastity, or lack of virtue of a class of citizens of any race, color, creed or religion." Writing for the Court, Felix Frankfurter argued that "a man's job and his educational opportunities and the dignity accorded him may depend as much on the reputation of the racial and religious group to which he willy-nilly belongs, as on his own merits." Beauharnais has never been overruled and has been cited in later cases (e.g., New York v. Ferber, 458 U.S. 747, 763 [1982]; R.A.V. v. City of St. Paul, 505 U.S. 377, 383 [1992]), though the Supreme Court's decision in New York Times Co. v. Sullivan (376 U.S. 254 [1964]) may place its authority in doubt.

${ }^{8}$ Note that laws with a similar aim but different structure might pass muster. Some scholars have suggested setting up public compensation funds for those injured by hate speech, for example, which would in itself be consistent with the priority of liberty: see Meyers (1995) and Schauer (1992) for detailed proposals.

${ }^{9}$ See, for example, Altman $(1993,306)$ and Peard $(2004,142-144,152)$. Peard's argument is especially striking: he develops criteria for assessing not only the harm and offense caused to listeners by hate speech but also the reasonableness of the speaker's conduct, which are derived from the "mediating maxims" used in the application of Joel Feinberg's harm and offense principles; these criteria bear a strong resemblance to Jeremy Bentham's criteria for measuring pleasure and pain. See Feinberg (1985, Volume 1, Chapter 5, and Volume 2, Chapter 8) and Bentham (1988, Chapter 4). Finally, J.S. Mill distinguishes himself from classical utilitarians like Henry Sidgwick on this issue: Mill boldly states "there is no parity between the feeling of a person for his own opinion, and the feeling of another who is offended at his holding it; no more than between the desire of a thief to take a purse, and the desire of the right owner to keep it" (Mill 1998, 93), while Sidgwick regards such assertions as evidence of Mill's heterodoxy—see Sidgwick (1981, 477-479). This suggests that Mill does not think his harm principle will justify limits on speech, at least where bodily security is not at stake; in those cases where it would be (e.g., use of "fighting words," shouting "fire" in a crowded theater, and inciting a riot), the harm principle would call for limits on speech-see, for example, Mill (1998, 62 [on incitement to riot]).

${ }^{10}$ Cf. Smart and Williams $(1973,37)$ : "There are in any case plenty of good utilitarian reasons for adopting the principle of fairness as an important, but not inviolable, rule of thumb." (emphasis added)
} 
in the U.S. by the long and painful struggle during the twentieth century for civil rights, especially in the South. To many, this struggle is politically defining, and its goals are not readily compromised. At the same time, however, they are strongly committed to free speech, suspicious of content restrictions, and highly supportive of the evolution of FirstAmendment doctrine toward ever greater protection of expression; moreover, they recognize the numerous ways in which the extension of speech rights has directly supported the fight for civil rights (e.g., New York Times v. Sullivan's redefinition of libel standards for public officials). The conflict here between free speech and equal opportunity is less a tension for liberal egalitarians than a dilemma-which of these two vital commitments should they sacrifice in reflective equilibrium?

When trapped in a dilemma, the natural human response is to look for an escape hatch. Perhaps the dilemma is a false one. Perhaps the hard choice can be avoided after all. As I shall discuss below, there seems to be such an escape hatch in this dilemma: nonideal theory. Briefly, the priority of liberty holds only under ideal conditions, viz. "strict compliance" (i.e., no existing injustices) and an absence of particular "historical contingencies" (e.g., an authoritarian political culture or severe economic underdevelopment) (Rawls 1999d, 54-55, 132, 214-220, 474-476; Rawls 1993, 7, 297). In nonideal conditions, the special conception of justice (with its lexical priority relations, including the priority of liberty) is relaxed and gives way to the general conception, which allows basic liberties to be traded off for opportunities and income so long as it is to "everyone's advantage" (Rawls 1999d, 54-55). ${ }^{11}$ Therefore, if we are currently under nonideal conditions, the dilemma that I described above may vanish: we might be able to curb hate speech for the sake of equal educational and employment opportunities without violating the priority of liberty because it does not hold yet.

Several philosophers have argued that we are indeed under nonideal conditions, given the existence of continuing systematic racial and sexual injustices that violate the "strict compliance" requirement of ideal theory, and that the philosophical community's focus on ideal theory and its demands is therefore oddly misdirected, even ethically blameworthy. As Diana Tietjens Meyers has pointed out:

Among the most widespread and glaring injustices facing our society are entrenched, cross-cutting systems of domination and subordination that enforce group-based social and economic exclusion. Since these injustices often make a mockery of ideal rights theory, I am convinced that there is an acute need for non-ideal normative theory, especially non-ideal rights theory. The basic rights we endorse should reflect social reality and should be capable of ameliorating real-world injustices.... When anchored in the abstractions of ideal theory, basic rights lose touch with this social reality and disadvantage many of the people who most urgently need the moral platform rights provide. (Meyers 1995, 203, 241) ${ }^{12}$

Charles Mills goes even further that this, suggesting that the assumptions of ideal theory are so at variance with reality that it is "really an ideology, a distortional complex of ideas, values, norms, and beliefs that reflects the nonrepresentative interests and experiences of a

\footnotetext{
${ }^{11}$ Rawls also emphasizes that such relaxations of the priority of liberty must be "progressive," in the sense that they help the society in question to attain ideal conditions and therefore the priority of liberty: "the equal liberties can be denied only when it is necessary to change the quality of civilization so that in due course everyone can enjoy these freedoms" (Rawls 1999d, 475).

12 Other philosophers have relatedly argued that, contra Rawls (1999d, 8, 216), there is no straightforward way to derive nonideal theory from ideal theory: see, for example, Phillips (1985).
} 
small minority of the national population - middle-to-upper class white males - who are hugely over-represented in the professional philosophical population" (Mills 2005, 172).

Over the remainder of this paper, I will explore three variations on the nonideal-theory strategy for escaping the dilemma, each of which builds upon and strengthens the previous one. I hope to show that none of them is successful and that liberal egalitarians are therefore genuinely trapped in a dilemma, forced in effect to choose between their liberalism and their egalitarianism, between liberty and equality. ${ }^{13}$ More controversially, I will also suggest that the nonideal-theory strategy could only be attractive to those already predisposed to sacrifice their liberalism to their egalitarianism; in fact, by the time we reach the third and final variant of this strategy, we will see that it implicitly affirms an illiberal form of egalitarianism. I conclude the paper with a brief examination of its implications for other policy areas, including the possibility of markets in both human organs and women's reproductive services.

\section{Nonideal-Theory Strategy, Variant 1: Partial Compliance, Plain and Simple}

This variant points out that the dilemma described above - the supposed tradeoff within ideal theory between EL and FEO, between free speech and equal educational and employment opportunities - is mediated by illegal discriminatory behavior, be it intentional or not. The causal chain is roughly as follows: speakers advocate bigoted doctrines; listeners are motivated by them to discriminate (consciously or subconsciously) against historically-oppressed groups; and FEO-implementation is thereby hampered, perhaps severely. Thus, violating the priority of liberty by restricting hate speech can promote the realization of FEO - hence the tradeoff between EL and FEO. Because this tradeoff is mediated by illegal behavior, though, it cannot be going on within ideal theory, which assumes strict compliance. Partial compliance means nonideal conditions, so there is no violation of the priority of liberty here: nonideal theory (in this case, Rawls's general conception of justice) permits tradeoffs between basic liberties and opportunities/income if they promote "everyone's interests," i.e., the priority of liberty does not hold within it. Therefore the alleged dilemma is a false one, at least when it is grounded on the causal chain presented above.

The unstated assumption in this argument, of course, is that strict compliance is just that: strict, meaning no illegal behavior, whether in the form of civil or criminal wrongs. This cannot be right, however. Strict compliance must be consistent with some level of illegal behavior (like illicit discrimination); otherwise, ideal theory would be utopian, as some crime is an unavoidable feature of human societies. As Rawls notes, "... we need an account of penal sanctions, however limited, even for ideal theory. Given the normal conditions of human life such arrangements are necessary" (Rawls 1999d, 212; emphasis added). Even

\footnotetext{
${ }^{13}$ Some liberal egalitarians might object to this characterization of the choice. Ronald Dworkin, for example, would insist that no such tradeoff exists: "the rights to liberty we regard as fundamental are a part or aspect of distributional equality, and so are automatically protected whenever equality is achieved. The priority of liberty is secured, not at the expense of equality, but in its name" (Dworkin 2002, 133). As I have shown, however, a tradeoff does exist between the (equal) basic liberty of free speech and equal educational and employment opportunities. Most people would describe this as a tradeoff between a type of liberty and a kind of equality, but nothing would be lost-except rhetorical punch-if we redescribed it as a tradeoff between species of social primary goods within a system of distributional equality. I shall retain the current characterization, however, because it fits common usage and is, well, rhetorically punchier.
} 
Huxley's Brave New World has its transgressors and enforcers. If this is true, however, then the tradeoff between EL and FEO could potentially take place within ideal theory:

1. Let $\alpha$ be the highest level of crime that is consistent with strict compliance; then $[0, \alpha]$ is the range of crime consistent with strict compliance.

2. Let $\beta$ (with $0<\beta \leq \alpha$ ) be the level of crime under the priority of liberty and therefore with the possible prevalence of bigoted doctrines (due at least in part to hate speech) and their encouragement of illicit discrimination, conscious or subconscious.

3. Let $\gamma$ (with $0 \leq \gamma<\beta \leq \alpha$ ) be the lower level of crime associated with a minor relaxation of the priority of liberty to allow restrictions on hate speech; the hypothesized lower level of crime would result from lower levels of illicit discrimination.

4. Therefore, there is potentially a tradeoff between EL and FEO (which is undermined by illicit discrimination) mediated by criminality within ideal theory.

If this argument is correct, then the dilemma remains intact, at least under certain circumstances: the illicit discrimination mediating the tradeoff between EL and FEO may, even when combined with other kinds of crime, remain within the range of ideal-theory criminality. The next variant of the nonideal-theory strategy denies this possibility by further developing Variant 1's claims.

\section{Nonideal-Theory Strategy, Variant 2: Partial Compliance plus Structural Oppression}

This variant grants that ideal theory must be consistent with at least some crime. What it denies, however, is that the illicit discrimination encouraged by hate speech remains within the bounds of ideal-theory criminality given the context within which it operates. This context is, to quote Diana Tietjens Meyers again, those "entrenched, cross-cutting systems of domination and subordination that enforce group-based social and economic exclusion" (Meyers 1995, 203). Hate speech achieves nearly all of its effectiveness through its insidious interaction with this structural oppression. As Patricia Mann and Lisa Schwartzman similarly describe the phenomenon:

The verbal aggressor taps into historically embedded structures of social oppression through the use of particular phrases and relies upon these deep structures to effect the damages of hate speech. It is possible to identify the systemic wrongness of the hate speech act...in terms of the aggressor's willful invocation of these deeply rooted social and psychological structures of domination and subordination. (Mann 1995, 258)

In order for racist and sexist social structures to serve as the context that enables hate speech to work, it need only be the case that language spoken in this context will be very likely to function in a way that subordinates, oppresses, or unjustly discriminates... The structures of racism and sexism - and those who speak with the force of these structures behind them-do have a certain degree of power and authority under current social, political, and historical conditions. (Schwartzman 2002, 430; cf. Delgado and Stefancic 1999, 66-68, and Reidy 2002)

To tie these observations to the causal chain discussed in the last section: the only reason that hate speech has such a powerful ability to provoke illicit discrimination is that it taps into pre-existing stereotypes, ones that reflect and reinforce extant patterns of group 
subordination and domination. Members of dominant groups are primed to be receptive to such speech because it validates their superior positions, and they are empowered to act upon it due to group-based inequalities in wealth and power. In short, the very effectiveness of hate speech in generating illicit discrimination and thereby hampering the implementation of FEO depends upon a social context (viz. group-based power relations and their symbolic counterparts) replete with ongoing injustices. The "partial compliance" here is rather partial indeed, and we are consequently in a nonideal world, where the priority of liberty does not hold. The dilemma is again a false one.

Scholars and activists who endorse something like this variant also tend to endorse two related claims. First, they usually think that in a world free of structural oppression hate speech would lose all or nearly all of its power and that restrictions on it would therefore be otiose; the potential harms of hate speech in such an ideal context (e.g., the occasional bigot inducing a few weak-minded people to discriminate) could be easily dealt with through antidiscrimination laws, which FEO already requires. ${ }^{14}$ Second, they often believe that such an ideal world is possible and that restrictions on hate speech are therefore temporary expedients that can be eliminated once structural oppression has been dismantled and racial and sexual justice achieved. ${ }^{15}$ Thus the full version of this variant has the requisite ideal/ nonideal structure: free-speech rights should (and in a coming ideal world will) receive priority, but they must be temporarily restricted under current, nonideal conditions in order to ensure equality of educational and employment opportunities and thereby lay the groundwork for a just — and fully liberal - society of the future.

My response to this variant of the nonideal-theory strategy cannot be as neatly conceptual as my response to the last one: I will have to make a variety of empirical claims, all of which will be contestable. To begin with what I hope will be a noncontroversial one, I would suggest that on the understanding of structural oppression offered above, all existing societies are under nonideal conditions. Consider, for instance, gender-based structural oppression. The Nordic countries (i.e., Denmark, Finland, Iceland, Norway, Sweden) are arguably the most gender-egalitarian societies in the world in terms of economic participation and opportunity, educational attainment, political empowerment, and health and survival. ${ }^{16}$ Nonetheless, each of these countries has a considerable legacy of sexism with far-reaching effects on the relations between men and women. To give but one example of such effects: the average woman's share of a married couple's housework is two-thirds or more in each of the major Nordic countries. ${ }^{17}$ These legacies are no doubt accompanied by stereotypes (e.g., regarding what qualifies as "women's work") that hate speech can tap into. If this is true even of the Nordic countries, then it is probably true of every country in the world. Thus, we come to the conclusion that due to gender-based structural oppression (and many other kinds as well), all existing societies are under nonideal conditions, and consequently the priority of liberty is in effect nowhere on earth.

\footnotetext{
${ }^{14}$ For example, see Meyers (1995, 222): "Indeed, if it weren't for the climate of racism, sexism, homophobia, and ethnocentrism in the United States, discriminatory verbal or pictorial abuse would not be seriously harmful."

${ }^{15}$ On the temporary, historically-contingent nature of hate-speech restrictions, see Delgado and Stefancic (1999, 129-131) and Mann (1995, 255-256). On the possibility of a world free of structural oppression, see Ross (1995, 156: "only when racism is purged from the mainstream and the margins of American society will true democracy be created"), Barry (1995, 322: "feminist consciousness...begins and is sustained in the conviction that a world without sexual exploitation is possible"), and Mills (2005, 181-182).

${ }^{16}$ These categories are from the Global Gender Gap Report 2007 of the World Economic Forum (Hausmann et al. 2007, 4). The Report ranks Sweden, Norway, Finland, and Iceland as the four most gender-egalitarian nations in the world (in descending order); Denmark comes in eighth (p. 7).

${ }^{17}$ See Knudsen and Wærness (2008, 103: Denmark: 66\%; Finland: 67\%; Norway: 73\%; Sweden: 66\%).
} 
This reading of the ideal/nonideal distinction differs from the one offered by Rawls, who said that "in our country today reasonably favorable conditions obtain, so that for us the priority of the basic liberties is required"; throughout his writings, Rawls seemed to assume that all of the more economically developed countries, at least, were under sufficiently ideal conditions for his two lexically-ordered principles of justice to apply (Rawls 1993, 297). ${ }^{18}$ As Charles Mills might suggest, however, perhaps Rawls was too complacent in his assessment: he may have underestimated the degree of injustice in these societies, failing to see the pervasive structural oppression in them owing to his position of privilege (Mills 2005, 172). ${ }^{19}$ The priority of liberty (and liberalism in its fullest form) might be better regarded as a goal towards which we, mired in systematic racial and sexual injustice, are still slowly slogging.

How distant would this goal then be, however, and what would be our prospects of ever reaching it? Once again, the history of the Nordic countries with respect to gender equality is not encouraging: even after many decades of extensive state intervention there on behalf of women (e.g., public provision of child and elder care, quotas for female membership in political bodies, educational initiatives, etc.) there is still a considerable legacy of sexism, as I pointed out above, and that legacy will likely remain intact for the foreseeable future. ${ }^{20}$ Although one can imagine societies in which particular group-based oppressions have been overcome (e.g., the oppression of white ethnics in the United States) or have never existed (e.g., oppression of the gray-eyed), it is considerably more difficult to imagine a society in which all of these oppressions and their associated identities and distrusts have been eliminated. The ideal/nonideal distinction on offer here bears some resemblance to that offered by Marx: a future world of superabundance, where the division of labor has been overcome and we can "hunt in the morning, fish in the afternoon, rear cattle in the evening, [and] criticise after dinner," is held out as the reward for the sacrifices of previous historical stages (Marx 1978a, 160, 197). While such an ideal world may not be strictly impossible, it is not going to happen anytime soon. If this is also true of a society free of all group-based oppressions, we might reasonably conclude, much as we did in the last section, that ideal theory surely cannot be this demanding-it cannot be utopian, or even effectively so, lest the liberal dream be forever deferred.

In my discussion of Variant 1, I suggested that ideal theory, in order to avoid utopianism, must make room for some amount of crime simpliciter, such as illicit discrimination. I now want to suggest that for the same reason it must make room for some quantity of discriminatory crime conditioned on the continued existence of group-based structural oppressions and their symbolic accoutrements. Whatever the threshold of compliance turns out to be, it should be such that ideal conditions, which trigger the priority of liberty, are attainable either now or in the near future for some nonempty set of societies. Otherwise, the commitment to liberalism here would be merely notional.

To be clear, I am not staking out the extreme position that no restrictions on liberty can be justified under nonideal conditions - far from it. As Rawls indicates, liberals can and must be willing to restrict basic liberties if and when doing so is necessary to bring about ideal conditions and therefore the applicability of ideal theory, including the priority of liberty; otherwise, liberals would rightly be vulnerable to the charge that liberal equality is

\footnotetext{
${ }^{18}$ He relatedly notes that the threshold for a people to be "well-ordered" is quite modest-e.g., "great wealth is not necessary to establish just (or decent) institutions"; see Rawls (1999a, 107 and $§ 15$ more generally).

${ }^{19}$ Needless to say, there is much counterevidence to this claim, the most obvious examples being his implicit concern for racial justice in his discussions of civil disobedience (Rawls 1999d, §§55, 57, 59) and explicit worries about the corrupting influence of money on politics (Rawls 1993, 359-363).

${ }^{20}$ For an overview of these interventions, see Kjeldstad (2001).
} 
merely formal, insensitive to the deep, structural inequalities that undermine the effective exercise of the basic liberties. ${ }^{21}$ Rather, I am suggesting that it is not enough for supporters of hate-speech restrictions simply to point out the ongoing existence of group-based structural oppressions and their symbolic appurtenances, as they must admit that these would exist to some degree even under ideal conditions; denial of this point would make them vulnerable to charges of utopianism, as argued above. They must instead indicate how much abatement of group-based structural oppression would be sufficient to bring about ideal conditions and thereby trigger priority for the basic liberties, especially free speech; additionally, they must demonstrate that this degree of abatement is possible either now or in the near future for some nonempty set of societies. ${ }^{22}$ I suspect that this challenge would not be taken up by defenders of hate-speech laws: as evidenced by the quotations from them used throughout this section, they would be very unlikely to admit that hate-speech victims could ever effectively exercise their basic liberties (including free speech) in the presence of structural oppression, no matter what the degree of abatement; their very language ("only when racism is purged from the mainstream and margins of American society"; "a world without sexual exploitation is possible") reveals a maximalism that is at odds with any lingering structural oppression (Ross 1995, 156; Barry 1995, 322). In order to avoid complicity with such oppression, they would probably seek refuge in the third and final variant.

\section{Nonideal-Theory Strategy, Variant 3: Liberalism as a Regulative Ideal}

This variant takes a new tack, but one that was implicit in the prior two. So far we have been tacitly assuming something that, according to this variant, we should question, viz. that the ideal/nonideal distinction (as well as its component strict/partial compliance distinction) should be seen as dichotomous rather than continuous. Surely, however, it is more reasonable to see it as continuous: why should reaching some threshold level of compliance suddenly trigger something as extreme as the lexical priority of liberty? Perhaps we should instead think of ideal theory and those conditions that make it possible (strict compliance and an absence of particular "historical contingencies") as approachable only in the limit. This modification would turn ideal theory into a "regulative ideal," an unattainable but nevertheless guiding and motivating model for political reform, like Plato's kallipolis according to one standard interpretation. ${ }^{23}$ In this case, the priority of liberty would never wholly apply: we would always be in a nonideal world, but as conditions improved its

\footnotetext{
${ }^{21}$ For an influential critique of this kind, see Marx (1978b). Rawls (1993, 324-331) implicitly replies to Marx's critique.

${ }^{22}$ One might argue that the burden of proof here has been placed on the wrong side of the debate: surely hate-speech victims and their scholarly defenders should not be obliged to draw a roadmap to an "ideal" world; rather, opponents of hate-speech laws should have to explain how any society with residual structural oppression could still secure the effective exercise of everyone's basic liberties. Recall, though, that (1) this debate is supposedly taking place within the bounds of liberal theory and (2) for the purposes of this paper we are assuming that liberals in general (like Mill, Rawls, and Scanlon in particular) defend a robust conception of free speech—one that protects hate speech as I have defined it—and give it a high priority in their theories, owing to its essential role in the development and exercise of intellectual autonomy. Given these facts, the burden of proof properly lies with those liberals who would restrict free speech, even for admittedly noble ends.

${ }^{23}$ In Plato's Republic, Socrates speaks of the kallipolis as a "pattern" for the perfectly just city but not as proof "that it's possible for these things to come into being"; rather, it is to serve as a model, with the best realizable city "most closely approximating it" (Plato 1991, 152-153 [472b-473b]). Charles Mills mentions Plato in a similar context (Mills 2005, 171).
} 
priority would increase. The dilemma would once again be a false one. This variant attempts to transmute the vice of utopianism into a virtue: rather than stubbornly demanding that ideal theory be an achievable objective in the face of evidence that it will be exceedingly difficult or impossible to achieve, it instead treats it as a directing pattern, one steadily approximated over time via tradeoffs among social primary goods that advance the cause of justice.

Insofar as liberalism is understood to involve the special priority of the basic liberties - a position endorsed explicitly by Rawls and implicitly by Mill, Scanlon, and others - this proposal is effectively an abandonment of liberalism. The previous variant at least kept alive the hope that ideal conditions would one day be achieved and liberalism would be fully implemented; this one, however, relinquishes such hopes, leaving nothing but a notional attachment to liberalism and a robust, substantive attachment to egalitarianism. Granted, this egalitarianism is one committed to increasing the weight assigned to the basic liberties over time as specified by the regulative ideal, but it must do so within the framework of the general conception of justice.

This temptation to expand the ambit of nonideal theory as the priority of liberty becomes uncomfortably binding - as it does by supposition in the hate-speech/FEO case - is in fact a kind of crypto-consequentialism, one prompted by a deep-seated unwillingness to subordinate FEO to EL, egalitarianism to liberalism, socioeconomic equality to basic liberties, especially freedom of speech. To see this, first consider Rawls's definition of the general conception of justice:

All social values - liberty and opportunity, income and wealth, and the social bases of self-respect - are to be distributed equally unless an unequal distribution of any, or all, of these values is to everyone's advantage. (Rawls 1999d, 54)

As Rawls makes clear by subsequent analysis, "everyone's advantage" should be interpreted as "the advantage of the least advantaged" (Rawls 1999d, §13). In other words, deviations from equality can only be justified if they redound to the benefit of the worst-off citizens; mere improvements in efficiency are insufficient to justify it. This Paretian species of egalitarianism guides the distribution of all social primary goods in a nonideal world, which Variant 3 has us permanently inhabiting.

Presumably, the general conception would encourage (re)distribution of these goods and sanction tradeoffs among the classes of goods (basic liberties, opportunities, etc.) until there were no further (re)distributions/tradeoffs available to enhance the lot of the worst-off, i.e., advantage to the least-advantaged should be maximized. Of what does this advantage consist, though? The bundle of social primary goods assigned to each member of the leastadvantaged class. But how is the worth of this bundle to be assessed, much less maximized, given its heterogeneous parts (liberties, opportunities, income, etc.)? This problem did not arise for the ideal theory, as its two lexically-ordered principles of justice forbade tradeoffs of liberties for opportunities (the priority of liberty) and of opportunities for income/wealth (the priority of FEO), and consequently the question of their comparability and fungibility never arose.

We can only maximize a single maximand, so to maximize the advantage derived from a bundle of social primary goods we need a unitary measure of its worth, an index that allows us to combine the worths of its diverse components. The construction of an index, however, requires a metric - some ground shared by all social primary goods, some common measure of their worth. Given the extreme heterogeneity of the goods in question, obvious candidate metrics will be such traditional measures as utility, welfare, well-being, etc. Once we recognize this fact, we will also realize that the general conception of justice has a 
decidedly consequentialist flavor: in effect, it defines the right as that which maximizes the good, understood as some index (likely welfarist in nature) of social primary goods for the least advantaged. ${ }^{24}$ As Rawls indicated in the first edition of Theory, improvements in the position of the least advantaged should lead us to assign a bigger weight to the basic liberties over time, because "the marginal significance for our good of further economic and social advantages diminishes relative to the interests of liberty"; nevertheless, the permanence of nonideal conditions under Variant 3 means that this weight will never become big enough for the priority of liberty to be attained (Rawls 1971, 542-3). ${ }^{25}$ The basic liberties will therefore remain forever hostage to the Paretian-egalitarian demands of a consequentialist general conception of justice.

\section{Conclusion}

Just as we may think of Rawls's difference principle as egalitarianism within the bounds of efficiency, so we might think of his larger political theory as egalitarianism within the bounds of liberalism. For Rawls and many others, a defining feature of liberalism is the commitment to autonomy and its institutional preconditions, including basic liberties such as freedom of speech. This commitment explains why the priority of liberty is a central feature of his ideal theory, one that limits the degree to which the demands of socioeconomic equality can be met. The variants of the nonideal-theory strategy we have examined tried to honor this commitment in the breach, but they were ultimately more successful at breaching than honoring. The dilemma with which we started this investigation remains intact: with regard to hate speech, liberal egalitarians must make a choice between free expression and equal educational and employment opportunities for historically-oppressed groups. There is ultimately no third option. If you would be a liberal only in some unattainable social world, then you are not really a liberal at all-you have already made your choice for equality over liberty.

This exploration of the uses and abuses of nonideal theory has implications stretching far beyond the debate over hate-speech restrictions. Consider, for example, scholarly discussions of markets in transplantable human organs and women's reproductive services and of whether they bring about an objectionable form of "commodification," one inconsistent with the equality and dignity of participants, especially sellers. ${ }^{26}$ Markets like these require rights of use and exclusion and powers of transfer over the human body and its labor, and one can show that these rights and powers either are among the basic liberties or are implications of them. Rawls himself notes that the case for "rights defining the integrity of the person" is more "compelling" than that for other basic liberties (e.g., political liberty) and argues strongly for the "important liberty of free choice of occupation" (Rawls 1999d, 217, 239-244). Moreover, consistent with Rawls's Kantian interpretation of justice as fairness, the rights and powers that are required to underwrite these markets

\footnotetext{
${ }^{24}$ Cf. the definition of teleology in Rawls (1999d, 21-22). Also see his discussion of "the priority problem" in $\S 8$ : once we rule out lexical priority relations as a means to constrain moral judgments, we are left only with some kind of teleology (e.g., utilitarianism) to do the job, as intuitionism leaves such judgments effectively unconstrained.

${ }^{25}$ Rawls later rejects his own line of argument here (Rawls 1993, 371n84), but only in the context of ideal theory. It remains entirely appropriate within nonideal theory, however, where the Kantian "hierarchy of interests" that supports the priority of liberty does not yet apply and our interests in liberty, wealth, etc., remain fungible.

${ }^{26}$ Among those scholars who have argued against such markets are Radin (1996) and Satz (1992).
} 
(which together constitute a conception of self-ownership) have been shown to follow from a Kantian interest in individual autonomy (Rawls 1999d, 221-227; Taylor 2004). Finally, innumerable other contemporary liberal theorists have either explicitly or implicitly endorsed this same package of rights and powers over the human body and its labor. ${ }^{27}$ As in the hate-speech case, liberals might be uncomfortably committed to defending the priority of these market liberties, at least under ideal conditions. ${ }^{28}$

Interestingly, critics of these very markets often come close to granting the last claim. For example, Margaret Jane Radin admits that "at present, perhaps, we cannot deny that it is possible that commodification by itself, without these other factors of social concern [viz. 'subordination or maldistribution'], would not seriously undermine personhood," and Debra Satz concedes that "under very different background conditions, in which men and women had equal power and had an equal range of choices, these [surrogate-motherhood] contracts would be less objectionable" and might even serve important social purposes (e.g., enabling "single persons, disabled persons, and same-sex families to have children") (Radin 1996, 162 ; Satz 1992, 128). ${ }^{29}$ What they deny, of course, is that these "background conditions" (e.g., no group-based oppressions) exist at present or will exist anytime soon; Radin, in fact, describes a world meeting such conditions as a "professor's hypothetical" (Radin 1996, 161). Given this unfortunate fact, the market liberties in question will have to be restricted, at least temporarily.

Notice the striking similarity of these arguments to Variant 2 (or in Radin's case perhaps Variant 3) of the nonideal-theory strategy: market liberties should (and in a coming ideal world will) be respected, but they must be temporarily restricted under current, nonideal conditions in order to advance socioeconomic equality (e.g., gender equality) and thereby lay the foundation for a just — and fully liberal — society of the future. The implicit ideal/ nonideal structure of these arguments for restricting some market liberties gives them a liberal patina, so to speak, allowing those who endorse them to avoid likely charges of illiberal egalitarianism. ${ }^{30}$ As I argued earlier, though, being committed to liberalism only in an effectively unattainable social world does not a liberal make. Again, those who affirm such arguments have already chosen equality over liberty.

Many other scholars, by contrast, are admirably frank about the illiberal implications of their egalitarianism and consequently have no use for a notional commitment to liberalism in an ideal world. For instance, Richard Arneson, an advocate of what he calls "egalitarian welfarism," contends that "the liberal egalitarian should bite [the] bullet. That is, the egalitarian should agree with Nozick that horizontal equity may require forced labor if there is to be redistribution to aid the needy" (Arneson 1992, 204; cf. Nozick 1974, 169-170). Egalitarians, in other words, should come to grips with the fact that their doctrine is in tension with a key liberal commitment, free labor. Arneson contends that they should therefore ditch this commitment and make their liberalism subservient to their egalitarianism, while Rawls argues the opposite, saying that "greater natural talents are not a collective

\footnotetext{
${ }^{27}$ For example, see Christman (1991, 39), Dworkin (1983, 39), Grünebaum (1987, 171), and Kernohan $(1990,22)$.

${ }^{28}$ Also as in the hate-speech case, these market liberties might need to be regulated for reasons internal to EL. For example, they could not be extended so as to allow voluntary, contractual slavery, as this would critically undermine the very thing that the basic liberties are supposed to protect, viz. our rational agency. ${ }^{29}$ Satz even concedes that prostitution "becomes 'degrading' only in a particular political and social context" (Satz 1992, 109n5); also see Satz (1995).

${ }^{30}$ To be fair, it is unclear that Radin has any desire to avoid such charges: she is sharply critical of liberal neutrality and favors state efforts to promote particular conceptions of "the good life" (Radin 1996, 73, 106, 209-211). Satz's case is more ambiguous: see Satz (1992, 109, 115-116, 123, 130).
} 
asset in the sense that society should compel those who have them to put them to work for the less favored" (Rawls 1999c, 231; cf. Rawls 1999b, 252-253). Perhaps even more bracing is Cécile Fabre's contention that liberal egalitarianism includes a principle of sufficiency, which demands that all persons be guaranteed a minimally flourishing life, and that this principle properly understood licenses not only forced labor to help the poor (in the form of civilian national-service requirements) but also the confiscation of scarce transplantable organs from cadavers and even living "donors" (Fabre 2006). Here is the subordination of liberty to equality with a breathtaking vengeance.

Such honesty has been rare but certainly not absent in the hate-speech literature. A few of the scholars and activists who have argued for restrictions on such speech have framed their support for these measures as part of a larger struggle against what one calls the "hegemony of liberal individualism" (Barry 1995, 318-319). In this spirit, Susan Brison challenges liberal egalitarians to choose equality over liberty in the domain of speech, just as they have done elsewhere:

As the libertarian Aaron Director has lamented, "free speech [is] the only area where laissez faire is still respectable." According to the liberal proponents of the autonomy defense of free speech, the restrictions on income spending imposed by redistributive taxation do not violate the autonomy even of libertarians who are morally opposed to mandatory taxation for redistributive purposes. Nor do the restrictions on the right to free association (such as mandatory desegregation of schools and restaurants or laws against certain male-only private clubs). Nor does government regulation of hiring practices (for example court-ordered affirmative action programs, or laws prohibiting race and sex discrimination). In all of these cases, liberty and equality are seen to be in conflict, and equality is determined to take priority. Why not also in the area of hate speech? (Brison 1998, 339)

Although I ultimately come down on the other side of this debate, I have offered few reasons in this paper for doing so; I have simply assumed that the basic liberties should have strong priority over socioeconomic equality. My purpose here has been a different one. Like Brison, I believe liberal egalitarians face fundamental choices between liberty and equality with regard to a host of controversial issues, including not only hate speech but also organ sales, surrogate motherhood, prostitution, civilian national-service programs, etc. This paper has tried to cut off a tempting escape route from these hard decisions that passes through nonideal theory. Liberal egalitarians must choose which of their component commitments will take priority in cases such as these, and that choice will reveal their true allegiance — or lack thereof — to liberalism.

Acknowledgments I wish to thank the editors of Ethical Theory and Moral Practice, two anonymous referees, Chad Van Schoelandt, and especially David Reidy (a conversation with whom prompted this piece) for their comments, criticisms, and candor. I am also grateful to Lord and Lady Sterling of Battersea for providing office space and residential support while I worked on this paper.

\section{References}

Altman A (1993) Liberalism and campus hate speech: a philosophical examination. Ethics 103:302-317 Arneson R (1992) Property rights in persons. Soc Philos Pol 9:201-230

Barnes RD (1995) Everyday racism and the campaign of hatred. In: Lederer LJ, Delgado R (eds) The price we pay: the case against racist speech, hate propaganda, and pornography. Hill and Wang, New York, pp 157-159 
Barry K (1995) Pornography and global sexual exploitation: a new agenda for feminist human rights. In: Lederer LJ, Delgado R (eds) The price we pay: the case against racist speech, hate propaganda, and pornography. Hill and Wang, New York, pp 315-322

Bentham J (1988) The principles of morals and legislation. Prometheus Books, Amherst

Brink DO (2001) Millian principles, freedom of expression, and hate speech. Leg Theor 7:119-157

Brison S (1998) The autonomy defense of free speech. Ethics 108:312-339

Christman J (1991) Self-ownership, equality, and the structure of property rights. Pol Theory 19:28-46

Delgado R, Stefancic J (1999) Must we defend Nazis? Hate speech, pornography, and the New First Amendment. New York University Press, New York

Dworkin R (1983) In defense of equality. Soc Philos Pol 1:24-40

Dworkin R (2002) Sovereign virtue: the theory and practice of equality. Harvard University Press, Cambridge

Fabre C (2006) Whose body is it anyway? Justice and the integrity of the person. Oxford University Press, New York

Feinberg J (1985) The moral limits of the criminal law, vol 4. Oxford University Press, New York

Freeman S (2007) Rawls. Routledge, London

Grünebaum J (1987) Private ownership. Routledge \& Kegan Paul, London

Hausmann R, Tyson LD, Saadia Z (2007) The global gender gap report. World Economic Forum, Geneva

Kant I (1996) What is enlightenment? In: Gregor M (trans) Practical philosophy. Cambridge University Press, Cambridge, pp 17-22

Kernohan A (1990) Rawls and the collective ownership of natural abilities. Can J Philos 20:19-28

Kjeldstad R (2001) Gender policies and gender equality. In: Kautto M et al (eds) Nordic welfare states in the European context. Routledge, London, pp 66-97

Knudsen K, Wærness K (2008) National context and spouses' housework in 34 countries. Eur Soc Rev 24:97-113

Lawrence CR (1995) Cross-burning and the sound of silence: anti-subordination theory and the First Amendment. In: Lederer LJ, Delgado R (eds) The price we pay: the case against racist speech, hate propaganda, and pornography. Hill and Wang, New York, pp 114-121

Mann PS (1995) Hate speech, freedom, and discourse ethics. In: Caudill DS, Gold SJ (eds) Radical philosophy of law: contemporary challenges to mainstream legal theory and practice. Humanities Press International, Highlands, pp 255-271

Marx K (1978a) The German ideology. In: Tucker RC (ed) The Marx-Engels reader. W. W. Norton, New York, pp 146-200

Marx K (1978b) On the Jewish question. In: Tucker RC (ed) The Marx-Engels reader. W. W. Norton, New York, pp 26-52

Meyers DT (1995) Rights in collision: a non-punitive, compensatory remedy for abusive speech. Law Philos 14:203-243

Michelman FI (1995) Civil liberties, silencing, and subordination. In: Lederer LJ, Delgado R (eds) The price we pay: the case against racist speech, hate propaganda, and pornography. Hill and Wang, New York, pp $272-276$

Mill JS (1998) On liberty and other essays. Oxford University Press, Oxford

Mills CW (2005) "Ideal theory" as ideology. Hypatia 20:165-184

Nozick R (1974) Anarchy, state, and utopia. Basic Books, New York

Peard T (2004) Regulating racist speech on campus. In: Sistare CT (ed) Civility and its discontents: civic virtue, toleration, and cultural fragmentation. University Press of Kansas, Lawrence, pp 140154

Phillips M (1985) Reflections on the transition from ideal to non-ideal theory. Noûs 19:551-570

Plato (1991) The republic. Basic Books, New York

Radin MJ (1996) Contestable commodities. Harvard University Press, Cambridge

Rawls J (1971) A theory of justice. Harvard University Press, Cambridge

Rawls J (1993) Political liberalism. Columbia University Press, New York

Rawls J (1999a) The law of peoples. Harvard University Press, Cambridge

Rawls J (1999b) Reply to Alexander and Musgrave. In: Freeman S (ed) Collected papers. Harvard University Press, Cambridge, pp 232-253

Rawls J (1999c) Some reasons for the maximin criterion. In: Freeman S (ed) Collected papers. Harvard University Press, Cambridge, pp 225-231

Rawls J (1999d) A theory of justice, rev edn. Harvard University Press, Cambridge

Reidy DA (2002) Hate crimes, oppression and legal theory. Publ Aff Q 16:259-285

Ross LJ (1995) Hate groups, African Americans, and the first amendment. In: Lederer LJ, Delgado R (eds) The price we pay: the case against racist speech, hate propaganda, and pornography. Hill and Wang, New York, pp 151-156 
Satz D (1992) Markets in women's reproductive labor. Philos Publ Aff 21:107-131

Satz D (1995) Markets in women's sexual labor. Ethics 106:63-85

Scanlon T (1972) A theory of freedom of expression. Philos Publ Aff 1:204-226

Schauer F (1992) Uncoupling free speech. Columbia Law Rev 92:1321-1357

Schwartzman LH (2002) Hate speech, illocution, and social context: a critique of Judith Butler. J Soc Philos $33: 421-441$

Sidgwick H (1981) The methods of ethics. Hackett Publishing, Indianapolis

Smart JJC, Williams B (1973) Utilitarianism: for and against. Cambridge University Press, Cambridge

Sunstein CR (1991) Preferences and politics. Philos Publ Aff 20:3-34

Taylor RS (2003) Rawls's defense of the priority of liberty: a Kantian reconstruction. Philos Publ Aff $31: 246-271$

Taylor RS (2004) A Kantian defense of self-ownership. J Pol Philos 12:65-78 